\title{
Benign epithelial tumor of salivary glands
}

INSERM

\section{Source}

INSERM. (1999). Orphanet: an online rare disease and orphan drug data base. Benign epithelial tumor of salivary glands. ORPHA:276148

Benign epithelial tumor of salivary glands is a rare neoplastic disease characterized by the presence of a tumor located in the parotid, sublingual, submandibular and/or minor salivary glands, which presents with a wide spectrum of clinical features depending on the location, size and type of salivary gland involved, usually manifesting as a slow-growing, painless, commonly solitary mass, rarely associated with facial nerve palsy or nasal/airway obstruction. 